\title{
Treatment of Displaced Intra-Articular Calcaneal Fractures with Closed Reduction and Percutaneous Screw Fixation
}

\author{
1 Department of Surgery 690, Radboud University Nijmegen Medical Centre, P.O. Box 9101, 6500HB Nijmegen, The \\ Netherlands. E-mail address for J.P.M. Frölke: j.frolke@chir.umcn.nl
}

Erasmus MC, University Medical Center Rotterdam, Rotterdam, the Netherlands Department of Surgery-Traumatology

To The Editor:

With great interest we read the article by Tomesen et al. considering the percutaneous reduction and screw fixation of 39 calcaneal fractures in 37 patients. We agree with the authors that the percutaneous treatment of displaced intraarticular calcaneal fractures is a valuable addition to the various treatment modalities for intra-articular calcaneal fractures with overall positive functional outcome (1). Although the complication rates, i.e. deep infections, reported in this study are higher than previously reported studies for percutaneous calcaneal surgery, the literature suggests that outcome has been similar for percutaneous treatment compared to open reduction and internal fixation via the extended lateral approach with even overall less wound complications (2).

While the authors do not find a correlation between the accuracy of the reduction (due to the small group of patients?) it is known from literature that an anatomical reduction confirmed with post-operative CT-imaging correlates with improved outcome in displaced intra-articular calcaneal fractures (3). Suggestions for better reduction might be the use of peroperative 3D-scanning or subtalar joint arthroscopy, which has shown high outcome scores in percutaneous reduction and internal fixation (4). One of the main drawbacks the authors report of the current technique described is a $40 \%$ need for implant removal. With respect to this need for implant removal, Zadravecz uses headless-distraction screws since approximately 2005 resulting in a low removal rate (5).

Furthermore the authors state there were only two slight modifications to the technique of Forgon and Zadravecz, there are however several. Zadravecz uses a three-point distraction technique (talus-cuboid and talus-calcaneus), he applies the distraction on both sides of the foot to facilitate the correction of varus deformity, and uses a blunt punch from plantar to correct step-off in the posterior talo-calcaneal joint, followed by the Cotton technique on the lateral wall to reduce width (5).

In conclusion, the discussion should not be whether percutaneous is a good technique, because that has been proven in numerous previous and larger studies. Nor should the discussion be whether percutaneous is better than open reduction. But the main, still unanswered, question is when to use which technique in a certain patient with a certain fracture-type. Conservative management, internal fixation (via a percutaneous approach, limited lateral approach, or via an extended lateral approach), and primary arthrodesis are all valuable techniques when used in the right patient with the right fracture-type. Future treatment should be tailored to the individual patient and his/her fracture, as not all calcaneal fractures are suitable to a single operative technique. References 1. Schepers T, van Lieshout EM, Ginai AZ, Mulder PG, Heetveld MJ, Patka P. Calcaneal fracture classification: a comparative study. J Foot Ankle Surg 2009;482:156-62. 2. DeWall M, Henderson CE, McKinley TO, Phelps T, Dolan L, Marsh JL. Percutaneous reduction and fixation of displaced intra-articular calcaneus fractures. J Orthop Trauma 2010;24-8:466-72. 3. Song KS, Kang CH, Min BW, Sohn GJ. Preoperative and postoperative evaluation of intra-articular fractures of the calcaneus based on computed tomography scanning. J Orthop Trauma 1997;11-6:435-40. 4. Woon CY, Chong KW, Yeo W, Eng-Meng Yeo N, Wong MK. Subtalar Arthroscopy and Fluorosocopy in Percutaneous Fixation of Intra-Articular Calcaneal Fractures: The Best of Both Worlds. J Trauma 2011. 5. Kadas I, Szita J, Zadravecz G, Hangody L, Doczi J. Stabilization of calcaneus fractures in a closed manner with a distraction screw. Joint Dis Rel Surg 2008;19-1:45-9. 